\title{
Cognitive emotion regulation, anxiety, and depression in infertile women: a cross- sectional study
}

\author{
Fatemeh Foroudifard ${ }^{1}$, Payam Amini ${ }^{2}$, Behnaz Navid ${ }^{3}$, Reza Omani-Samani ${ }^{4}$, Mahdi Sepidarkish ${ }^{5}$ and \\ Saman Maroufizadeh ${ }^{6^{*}}$ (D)
}

\begin{abstract}
Background: Cognitive strategies play an important role in the prevention of psychological disorders. The aim of this study was to examine the relationships of cognitive emotion regulation with anxiety and depression symptoms in a sample of infertile women in Iran.

Results: According to correlation analysis, all adaptive strategies (i.e., acceptance, positive refocusing, refocus on planning, positive reappraisal, and putting into perspective), except for Acceptance strategy, were indirectly related to both anxiety and depression symptoms. Conversely, four maladaptive strategies (i.e., self-blame, rumination, catastrophizing, and other-blame) were positively related to anxiety and depression symptoms. After controlling for demographic/infertility information, hierarchical regression analyses indicated that acceptance, rumination, and positive refocusing subscales were significantly associated with anxiety; and refocus of planning was related to depression.

Conclusion: In sum, cognitive emotion regulation strategies appeared to be related to anxiety and depression symptoms in women suffering from infertility. These results suggest the use of cognitive therapy to reduce the anxiety and depression in these women.
\end{abstract}

Keywords: Cognitive emotion regulation, Depression, Anxiety, Infertility

\section{Background}

Infertility is defined as "the failure to achieve a clinical pregnancy after 12 months or more of regular unprotected sexual intercourse" [1] and affects $9 \%$ of reproductive-aged couples worldwide [2]. It is a negative life event and therefore may be leading to negative psychological consequences. Anxiety and depression are two of the most commonly occurring psychological disorders in infertile patients [3, 4]. Infertility and its treatments also may adversely affect marital satisfaction, life satisfaction, and quality of life [5-7]. In addition, it is widely acknowledged that women are more affected than

\footnotetext{
* Correspondence: saman.maroufizadeh@gmail.com

${ }^{6}$ Department of Biostatistics, School of Nursing and Midwifery, Guilan University of Medical Sciences, Rasht, Iran

Full list of author information is available at the end of the article
}

men by infertility, particularly in developing countries. For example, in a study conducted among infertile couples in Iran, women were more likely to have depression symptoms and impaired quality of life than men [8]. A growing body of research indicated that psychological distress in response to the experience of adverse life events may be correlated with the cognitive emotion regulation strategies (or cognitive coping) that someone uses to deal with that negative life event [9].

Cognitive emotion regulation strategies can be defined as "the conscious mental strategies individuals use to handle the intake of emotionally arousing information" $[9,10]$. Several individual emotion-regulation strategies have been hypothesized to be risk factors for or protective factors against psychopathology. To measure cognitive coping, Garnefski et al. [10] developed the Cognitive 
Emotion Regulation Questionnaire (CERQ). The CERQ measures nine different cognitive emotion regulation strategies including five adaptive strategies (acceptance, positive refocusing, refocus on planning, positive reappraisal, and putting into perspective) and four maladaptive strategies (self-blame, rumination, catastrophizing, and other-blame). The definitions of these strategies were as follows: (1) self-blame, referring to "thoughts of putting the blame of what you have experienced on yourself"; (2) other-blame, referring to "thoughts of putting the blame of what you have experienced on the environment or another person"; (3) rumination, referring to "thinking about the feelings and thoughts associated with the negative event"; (4) catastrophizing, referring to "thoughts of explicitly emphasizing the terror of what you have experienced"; (5) putting into perspective, referring to "downgrading the importance of the event"; (6) positive refocusing, referring to "thinking about positive experiences instead of thinking about the actual event";(7) positive reappraisal, referring to "thoughts of giving the event a positive meaning in terms of personal growth"; (8) acceptance, referring to "thoughts of resigning yourself to what has happened"; and (9) refocus on planning, referring to "thinking about what steps to take and how to handle the negative event" $[9,10]$. Previous studies suggest that maladaptive strategies are commonly correlated with depression and anxiety symptoms and have formed the basis of studies on the cognitive model of depression [11]. Previous researches have shown that maladaptive strategies such as ruminating, self-blame, and catastrophizing are positively correlated to depression, anxiety, and/or other relevant measures, while adaptive strategies such as positive refocusing and positive reappraisal are negatively related [12-15].

As cognitive strategies play an important role in the development, maintenance, and exacerbation of depression and anxiety symptoms, it seems important to determine cognitive emotion regulation strategies correlated with vulnerability to depression and anxiety [15]. Therefore, the current study was conducted to identify cognitive emotion regulation strategies associated with anxiety and depression among infertile women.

\section{Methods}

\section{Participants and study design}

This was a cross-sectional study performed in the Royan Institute, a referral fertility center in Tehran, Iran, from February to March 2017. Participants were a sample of 240 women with infertility. The eligibility criteria were as follows: (1) women aged 18-45 years, (2) experiencing fertility problems, and (3) ability to read and write in Persian. The study was approved by the Ethics Committee of the Royan Institute and verbal informed consent to participate in the study was obtained from the participants.

\section{Instruments}

\section{Demographic and clinical information}

Before completing the main questionnaires related to this study, demographic, and fertility information including age, marital duration, employment statue, educational level, infertility duration, cause of infertility, previous treatment failures, and history of abortion were gathered.

\section{Cognitive emotion regulation questionnaire (CERQ)}

The CERQ is a 36-item self-report questionnaire that measures the cognitive aspects of emotion regulation [10]. It consists of nine subscales: self-blame, acceptance, rumination, positive refocusing, refocus on planning, positive reappraisal, putting into perspective, catastrophizing, and other-blame. All CERQ subscales consist of 4 items, with each item rated on a 5-point Likert scale, ranging from 1 (almost never) to 5 (almost always).

\section{Hospital anxiety and depression scale (HADS)}

The HADS is a 14-item self-report instrument. It consists of two subscales (each of 7 items), measuring the level of anxiety and depression symptoms. Each item is measured on a 4-point Likert scale ranging from 0 to 3 . The HADS subscale scores can range from 0 to 21, with higher scores indicating more anxiety or depression symptoms. The Persian version of HADS is reported to have adequate psychometric properties in infertile people [16]. In the current study, internal consistency reliability was good for anxiety $(\alpha=0.850)$ and depression $(\alpha=0.782)$ subscales.

\section{Statistical analysis}

Statistical analysis conducted using IBM SPSS Statistics for Windows, Version 22.0 (IBM Corp., Armonk, NY, USA). Pearson's correlation coefficient was calculated to evaluate the relationships among the major variables. Hierarchical multiple linear regression was used to determine the relationships of CERQ subscales with anxiety and depression, controlling for demographic/clinical variables. Two steps were performed: (1) in the first step, the demographic/clinical variables were entered in the first block to control for their effects on anxiety and depression; (2) in the second step, the nine CERQ subscales were entered in the second block. In addition, anxiety and depression models were checked for multicollinearity by using tolerance and variance inflation factor (VIF). A tolerance $<0.1$ and/or VIF $>5$ indicates a multicollinearity problem. None of the variables showed significant multicollinearity. 


\section{Results}

\section{Participant characteristics}

In total, 240 women participated in this study. The mean age of the women was $32.78(\mathrm{SD}=5.44)$ years, and mean infertility duration was $6.81(\mathrm{SD}=4.30)$ years. The majority were housewives (92.6\%) and approximately half of the women had male factor infertility (47.5\%). Of the participants, $39.6 \%$ had a university education, $66.2 \%$ reported at least one failure in previous infertility treatment, and $22.1 \%$ reported a history of abortion (Table 1 ).

\section{Descriptive statistics and correlations among study variables}

Means, SDs, and correlations for HADS subscales and CERQ subscales are presented in Table 2. The mean score of anxiety and depression was 7.35 ( $\mathrm{SD}=4.26)$ and 5.58 ( $\mathrm{SD}=3.77)$, respectively. Using the HADS value of 8 as a cut-off point, the prevalence rates of anxiety and depression were $41.7 \%$ and $29.6 \%$, respectively. As seen in Table 2, all adaptive strategies, expect for acceptance strategy, were indirectly related to both anxiety and depression scores. Conversely, four maladaptive strategies were positively related to anxiety and depression scores. In general, the highest and lowest mean

Table 1 Demographic and clinical characteristics of the participants $(n=240)$

\begin{tabular}{|c|c|}
\hline & mean \pm SD or $n(\%)$ \\
\hline Age (years) & $32.78 \pm 5.44$ \\
\hline Duration of marriage (years) & $8.50 \pm 4.49$ \\
\hline Duration of infertility (years) & $6.81 \pm 4.30$ \\
\hline \multicolumn{2}{|l|}{ Educational level } \\
\hline Primary & $57(23.8)$ \\
\hline Secondary & $88(36.7)$ \\
\hline University & 95 (39.6) \\
\hline \multicolumn{2}{|l|}{ Occupation } \\
\hline Housewife & $196(81.7)$ \\
\hline Employed & $44(18.3)$ \\
\hline \multicolumn{2}{|l|}{ Cause of infertility } \\
\hline Male factor & $114(47.5)$ \\
\hline Female factor & $53(22.1)$ \\
\hline Both & $44(18.3)$ \\
\hline Unexplained & $29(12.1)$ \\
\hline \multicolumn{2}{|l|}{ Failure of previous treatment } \\
\hline No & $81(33.8)$ \\
\hline Yes & $159(66.2)$ \\
\hline \multicolumn{2}{|l|}{ History of abortion } \\
\hline No & $187(77.9)$ \\
\hline Yes & $53(22.1)$ \\
\hline
\end{tabular}

SD standard deviation scores of CERQ subscales were observed in "adaptive strategies" and "maladaptive strategies," respectively.

\section{Multiple linear regression analysis}

Hierarchical multiple linear regression analysis was used to identify variables that were significantly independently associated with anxiety and depression scores (Table 3). Based on the standardized regression coefficients in block 1 , only the history of abortion was significantly related to anxiety $(\beta=0.144, P=0.039)$. The model $R^{2}$ when demographics/infertility variables were in the anxiety model was equal to 0.055 , suggesting that $5.5 \%$ of the variance in anxiety was explained by these variables. In block 2, among the CERQ subscales, acceptance and positive refocusing subscales were negatively correlated with anxiety $(\beta=-0.146, P=0.026 ; \beta=-0.234, P=$ 0.014 , respectively) and rumination subscale was positively correlated with anxiety $(\beta=0.271, P=0.001)$. When the CERQ subscales were added in the model, there was a significant improvement in the model $\left(\Delta R^{2}\right.$ $=0.260, F$ change $=9.284, P<0.001)$. More specifically, an additional $26.0 \%$ of the variance in anxiety was explained by the CERQ subscales.

For depression, in block 1, marital duration and educational level were significantly related to depression $(\beta=$ $-0.246, P=0.028 ; \beta=-0.148, P=0.042$, respectively). Furthermore, the groups of women with female and unknown causes of infertility reported higher depression than women with male factor infertility. The model $R^{2}$ in this step was 0.094, suggesting that $9.4 \%$ of the variance in depression was explained by demographics and infertility information. In block 2 , among the CERQ subscales, only the refocus on planning subscale was negatively correlated with depression $(\beta=-0.203, P=$ 0.027). When the CERQ subscales were added in the model, there was a significant improvement in the model $\left(\Delta R^{2}=0.229, F\right.$ change $\left.=8.256, P<0.001\right)$. More specifically, an additional $22.9 \%$ of the variance in depression was explained by the CERQ subscales. The total proportion of variance explained in anxiety and depression explained by all the independent variables was $31.5 \%$ and $32.3 \%$, respectively (Table 3 ).

\section{Discussion}

The main objective of the present study was to examine the relationship of cognitive emotion regulation with anxiety and depression symptoms in women with infertility. In the present study, the prevalence of anxiety and depression symptoms were $41.7 \%$ and $29.6 \%$, respectively, which are consistent with previous studies in Iran $[3,4]$. We investigated the relationships of demographic and infertility variables with anxiety and depression. Among demographic and infertility variables, only the history of spontaneous abortion was significantly related 
Table 2 Means, standard deviations, and correlations among study variables $(n=240)$

\begin{tabular}{|c|c|c|c|c|c|c|c|c|c|c|c|c|}
\hline & Mean (SD) & 1 & 2 & 3 & 4 & 5 & 6 & 7 & 8 & 9 & 10 & 11 \\
\hline 1. Anxiety & $7.35(4.26)$ & 1 & & & & & & & & & & \\
\hline 2. Depression & $5.58(3.77)$ & $0.50^{* * *}$ & 1 & & & & & & & & & \\
\hline 3. Self-blame & $7.55(3.73)$ & $0.34^{* * *}$ & $0.38^{* * *}$ & 1 & & & & & & & & \\
\hline 4. Acceptance & $12.15(3.72)$ & -0.03 & -0.03 & $0.19^{* *}$ & 1 & & & & & & & \\
\hline 5. Rumination & $12.28(3.58)$ & $0.37^{* * *}$ & $0.27^{* * *}$ & $0.46^{* * *}$ & $0.29^{* * *}$ & 1 & & & & & & \\
\hline 6. Positive refocusing & $13.07(3.99)$ & $-0.35^{* * *}$ & $-0.41^{* * *}$ & $-0.30^{* * *}$ & 0.09 & -0.09 & 1 & & & & & \\
\hline 7. Refocus on planning & $14.09(3.77)$ & $-0.27^{* * *}$ & $-0.39^{* * *}$ & $-0.19^{* *}$ & $0.17^{* *}$ & 0.05 & $0.72^{* * *}$ & 1 & & & & \\
\hline 8. Positive reappraisal & $13.43(4.07)$ & $-0.27^{* * *}$ & $-0.38^{* * *}$ & $-0.33^{* * *}$ & $0.17^{* *}$ & -0.06 & $0.69^{* * *}$ & $0.69^{* * *}$ & 1 & & & \\
\hline 9. Putting into perspective & $12.68(3.71)$ & $-0.21^{* * *}$ & $-0.34^{* * *}$ & $-0.25^{* * *}$ & $0.27^{* * *}$ & -0.06 & $0.54^{* * *}$ & $0.47^{* * *}$ & $0.56^{* * *}$ & 1 & & \\
\hline 10. Catastrophizing & $9.57(3.88)$ & $0.38^{* * *}$ & $0.37^{* * *}$ & $0.55^{* * *}$ & $0.23^{* * *}$ & $0.59^{* * *}$ & $-0.25^{* * *}$ & $-0.15^{* *}$ & $-0.28^{* * *}$ & $-0.24^{* * *}$ & 1 & \\
\hline 11. Other-blame & $6.49(3.16)$ & $0.30^{* * *}$ & $0.29^{* * *}$ & $0.46^{* * *}$ & 0.05 & $0.41^{* * *}$ & $-0.16^{*}$ & -0.05 & $-0.14^{*}$ & $-0.18^{* *}$ & $0.48^{* * *}$ & 1 \\
\hline
\end{tabular}

Note. $S D$ standard deviation

${ }^{*} p<0.05 ;{ }^{* *} p<0.01 ;{ }^{* * *} p<0.001$

Table 3 Results of hierarchical multiple linear regressions, including factors related to anxiety and depression

\begin{tabular}{|c|c|c|c|c|c|c|c|c|}
\hline & \multicolumn{4}{|l|}{ Anxiety } & \multicolumn{4}{|c|}{ Depression } \\
\hline & $\mathrm{B}$ & SE & Beta & $P$ & $B$ & SE & Beta & $P$ \\
\hline \multicolumn{9}{|l|}{ Block 1: Demographic/fertility variables } \\
\hline Age (years) & 0.007 & 0.034 & 0.014 & 0.839 & 0.028 & 0.029 & 0.064 & 0.331 \\
\hline Marital duration (years) & -0.154 & 0.108 & -0.162 & 0.155 & -0.206 & 0.093 & -0.246 & 0.028 \\
\hline Job (employed vs housewife) & -0.760 & 0.804 & -0.069 & 0.346 & -0.276 & 0.697 & -0.028 & 0.693 \\
\hline Educational level (academic vs non-academic) & -0.329 & 0.643 & -0.038 & 0.609 & -1.137 & 0.557 & -0.148 & 0.042 \\
\hline Infertility duration (years) & 0.133 & 0.114 & 0.134 & 0.246 & 0.188 & 0.099 & 0.214 & 0.059 \\
\hline \multicolumn{9}{|l|}{ Cause of infertility } \\
\hline \multicolumn{9}{|l|}{ Male factor (Ref) } \\
\hline Female factor & 1.110 & 0.731 & 0.108 & 0.131 & 1.500 & 0.634 & 0.165 & 0.019 \\
\hline Both & -0.094 & 0.763 & -0.009 & 0.902 & 0.769 & 0.661 & 0.079 & 0.246 \\
\hline Unknown & 1.454 & 0.916 & 0.111 & 0.114 & 1.808 & 0.794 & 0.157 & 0.024 \\
\hline Previous treatment failures (yes vs. no) & 0.058 & 0.619 & 0.006 & 0.925 & 0.567 & 0.536 & 0.071 & 0.291 \\
\hline History of abortion (yes vs. no) & 1.477 & 0.689 & 0.144 & 0.033 & 0.361 & 0.597 & 0.040 & 0.546 \\
\hline Model characteristics & \multicolumn{4}{|l|}{$R^{2}=0.055$} & \multicolumn{4}{|c|}{$R^{2}=0.094$} \\
\hline \multicolumn{9}{|l|}{ Block 2: CERQ subscales } \\
\hline Self-blame & 0.094 & 0.089 & 0.082 & 0.293 & 0.139 & 0.078 & 0.138 & 0.077 \\
\hline Acceptance & -0.167 & 0.074 & -0.146 & 0.026 & -0.042 & 0.065 & -0.042 & 0.518 \\
\hline Rumination & 0.322 & 0.094 & 0.271 & 0.001 & 0.113 & 0.083 & 0.107 & 0.177 \\
\hline Positive refocusing & -0.250 & 0.101 & -0.234 & 0.014 & -0.145 & 0.089 & -0.153 & 0.106 \\
\hline Refocus on planning & -0.147 & 0.103 & -0.130 & 0.156 & -0.203 & 0.091 & -0.203 & 0.027 \\
\hline Positive reappraisal & 0.064 & 0.097 & 0.061 & 0.509 & 0.009 & 0.085 & 0.009 & 0.919 \\
\hline Putting into perspective & 0.036 & 0.087 & 0.031 & 0.679 & -0.051 & 0.076 & -0.051 & 0.502 \\
\hline Catastrophizing & 0.160 & 0.091 & 0.146 & 0.080 & 0.081 & 0.080 & 0.083 & 0.314 \\
\hline Other-blame & 0.084 & 0.093 & 0.062 & 0.365 & 0.108 & 0.082 & 0.090 & 0.188 \\
\hline Model characteristics & \multicolumn{4}{|c|}{$\begin{array}{l}R^{2}=0.315, \Delta R^{2}=0.260, F \text { change }=9.284, p< \\
0.001\end{array}$} & \multicolumn{4}{|c|}{$\begin{array}{l}R^{2}=0.323, \Delta R^{2}=0.229, F \text { Change }=8.256, p< \\
0.001\end{array}$} \\
\hline
\end{tabular}


to anxiety scores, as women with a history of spontaneous abortion had high anxiety symptoms. Our findings showed that depression was more common in women with short marital duration as well as women with low educational level and women with female factor and unknown cause of infertility $[3,17]$.

Generally, our findings show that the adaptive strategies were reported to have been used more often than the maladaptive strategies. Among the adaptive strategies, acceptance was the least frequently implemented, and among the maladaptive strategies, other-blame was the least frequently implemented. These findings are consistent with previous studies [10, 18-21].

According to the bivariate correlation analysis, all CERQ subscales, except for acceptance, correlated significantly with both anxiety and depression. Positive refocusing, refocus on planning, positive reappraisal, and putting into perspective correlated negatively with both anxiety and depression symptoms. Self-blame, rumination, catastrophizing, and other-blame correlated positively with anxiety and/or depression symptoms. When looking at the strengths of the correlations, the maladaptive strategies were more strongly related to depression than anxiety.

Among cognitive emotion regulation strategies, only refocus on planning strategy was independently negatively correlated with depression in multivariate analyses after controlling for demographic and infertility variables. In multivariate analysis, more engagement of rumination as well as less engagement of acceptance and positive refocusing independently contributed to anxiety. This finding corresponds to findings reported in previous studies performed in various populations [12-15, 18, 19, 21, 22].

One implication of the current study is that it may not be appropriate to consider the Acceptance subscale as an adaptive strategy, as recommended by Garnefski et al. [10]. Although we found partial support for the adaptive role of acceptance in that it was positively related to some other adaptive strategies (i.e., refocus on planning, positive reappraisal, and putting into perspective), acceptance was also positively correlated with some maladaptive strategies (i.e., self-blame, rumination, and catastrophizing strategies). In addition, among 9 subscales of CERQ, only acceptance subscale was not correlated with anxiety and depression symptoms according to the univariate analysis. One possible explanation is that the acceptance items (e.g., "I think that I have to accept that this has happened," "I think that I have to accept the situation," etc.) may reflect a degree of hopelessness. Therefore, acceptance strategy may be adaptive only in certain conditions. Due to the abovementioned findings, we suggest interpreting this subscale with caution. Whether acceptance strategy is adaptive or maladaptive depends on the circumstance and the type of mood under study. This finding is in line with a study performed by Martin and Dahlen [23].

For future research, we recommend comparing cognitive emotion regulation strategies by gender, cause of infertility. In addition, it would be useful to set up randomized controlled trials in which anxiety and depression symptoms in patients with infertility are compared before and after cognitive behavioral therapy.

The present study has several limitations that need to be noted. First, it was a single-center study utilizing only infertile women. Second, the sample size was relatively small. So, the generalizability of the findings may be limited by the characteristics of our study sample. Third, all variables were measured via self-report instruments. This may have caused bias. Forth, because of the crosssectional nature of the study, it is not possible to infer causality between study variables.

\section{Conclusion}

Our findings provide further empirical support for the relationship between cognitive emotion regulation strategies and symptoms of anxiety and depression in infertile women and evidence for designing emotion regulation therapies such as cognitive behavioral therapy (CBT) to reduce the anxiety and depression symptoms in these women.

\section{Abbreviations \\ CERQ: Cognitive Emotion Regulation Questionnaire; HADS: Hospital Anxiety and Depression Scale; SD: Standard deviations; VIF: Variance inflation factor}

\section{Acknowledgements}

The authors express their appreciation to the infertile women who participated in this research study and to the Royan Institute, Tehran, Iran, for its kind cooperation in data collection.

\section{Authors' contributions}

FF and SM: Study design and conception; Data analysis and interpretation; Manuscript writing; ROS, and BN: Study design and conception, data acquisition, and manuscript writing. PA, AAH, and MS: Study design and conception; Data interpretation; Manuscript writing; All authors approved the final version of the manuscript for submission.

\section{Funding}

This research received no specific grant from any funding agency in the public, commercial, or not-for-profit sectors.

\section{Availability of data and materials}

The datasets used and/or analyzed during the current study are available from the corresponding author on reasonable request.

\section{Ethics approval and consent to participate}

The Ethics Committee of Royan Institute, Tehran, Iran, approved this study (registration number: IR.ACECR.ROYAN.REC.1395.141). All the women were informed about the aim of the study verbally, and all the ethical points were written at the above of the questionnaires including confidentiality of the data, involuntariness of the cases, and no relation of this study to their treatment process. Thus, freely filling the questionnaires was considered as consent.

Consent for publication

Not applicable. 


\section{Competing interests}

The authors declare that they have no competing interests.

\section{Author details}

'Department of Clinical Psychology, College of Humanities and Social Sciences, Tehran Science and Research Branch, Islamic Azad University, Tehran, Iran. ${ }^{2}$ Department of Biostatistics and Epidemiology, School of Public Health, Ahvaz Jundishapur University of Medical Sciences, Ahvaz, Iran. ${ }^{3}$ Reproductive Epidemiology Research Center, Royan Institute for Reproductive Biomedicine, ACECR, Tehran, Iran. ${ }^{4}$ Department of Medical Ethics and Law, Reproductive Biomedicine Research Center, Royan Institute for Reproductive Biomedicine, ACECR, Tehran, Iran. ${ }^{5}$ Department of Biostatistics and Epidemiology, Babol University of Medical Sciences, Babol, Iran. ${ }^{6}$ Department of Biostatistics, School of Nursing and Midwifery, Guilan University of Medical Sciences, Rasht, Iran.

Received: 4 March 2020 Accepted: 18 June 2020

Published online: 01 July 2020

\section{References}

1. Zegers-Hochschild F, Adamson G, De Mouzon J, Ishihara O, Mansour R, Nygren K, Sullivan E (2009) Sexual and reproductive health. Hum Reprod 24(11):1-5

2. Boivin J, Bunting L, Collins JA, Nygren KG (2007) International estimates of infertility prevalence and treatment-seeking: potential need and demand for infertility medical care. Hum Reprod 22(6):1506-1512

3. Omani-Samani R, Ghaheri A, Navid B, Sepidarkish M, Maroufizadeh S (2018) Prevalence of generalized anxiety disorder and its related factors among infertile patients in Iran: a cross-sectional study. Health Qual Life Outcomes 16(1):129

4. Omani-Samani R, Maroufizadeh S, Almasi-Hashiani A, Amini P (2018) Prevalence of depression and its determinant factors among infertile patients in Iran based on the PHQ-9. Middle East Fertil Soc J 23(4):460-463

5. Omani-Samani R, Maroufizadeh S, Ghaheri A, Amini P, Navid B (2018) Reliability and validity of the Kansas marital satisfaction scale (KMSS) in infertile people. Middle East Fertil Soc J 23(2):154-157

6. Maroufizadeh S, Ghaheri A, Samani RO, Ezabadi Z (2016) Psychometric properties of the satisfaction with life scale (SWLS) in Iranian infertile women. Int J Reprod Biomed 14(1):57-62

7. Maroufizadeh S, Ghaheri A, Amini P, Samani RO (2017) Psychometric properties of the fertility quality of life instrument in infertile Iranian women. Int J Fertil Steril 10(4):371-379

8. Maroufizadeh S, Hosseini M, Foroushani AR, Omani-Samani R, Amini P (2018) The effect of depression on quality of life in infertile couples: an actor-partner interdependence model approach. Health Qual Life Outcomes 16(1):73

9. Garnefski N, Kraaij V (2006) Relationships between cognitive emotion regulation strategies and depressive symptoms: a comparative study of five specific samples. Pers Individ Dif 40(8):1659-1669

10. Garnefski N, Kraaij V, Spinhoven P (2001) Negative life events, cognitive emotion regulation and emotional problems. Pers Individ Dif 30(8):13111327

11. Beck JS (2011) Cognitive behavior therapy: basics and beyond. New York: Guilford press

12. Bruggink A, Huisman S, Vuijk R, Kraaij V, Garnefski N (2016) Cognitive emotion regulation, anxiety and depression in adults with autism spectrum disorder. Res Autism Spectr Disord 22:34-44

13. Garnefski N, Kraaij V, Schroevers M, Aarnink J, van der Heijden D, van Es S, Van Herpen M, Somsen G (2009) Cognitive coping and goal adjustment after first-time myocardial infarction: relationships with symptoms of depression. Behav Med 35(3):79-86

14. Kraaij V, Pruymboom E, Garnefski N (2002) Cognitive coping and depressive symptoms in the elderly: a longitudinal study. Aging Ment Health 6(3):275281

15. Min J-A, Yu JJ, Lee C-U, Chae J-H (2013) Cognitive emotion regulation strategies contributing to resilience in patients with depression and/or anxiety disorders. Compr Psychiatry 54(8):1190-1197

16. Amini P, Maroufizadeh S, Samani RO (2017) Evaluating the factor structure, item analyses, and internal consistency of hospital anxiety and depression scale in Iranian infertile patients. Int J Reprod Biomed 15(5):287-296
17. Maroufizadeh S, Ghaheri A, Almasi-Hashiani A, Mohammadi M, Navid B, Ezabadi Z, Samani RO (2018) The prevalence of anxiety and depression among people with infertility referring to Royan Institute in Tehran, Iran: a cross-sectional questionnaire study. Middle East Fertil Soc J 23(2):103-106

18. Cakmak A, Cevik E (2010) Cognitive emotion regulation questionnaire: development of Turkish version of 18-item short form. Afr J Bus Manag 4(10):2097

19. Domínguez-Sánchez FJ, Lasa-Aristu A, Amor PJ, Holgado-Tello FP (2013) Psychometric properties of the Spanish version of the cognitive emotion regulation questionnaire. Assessment 20(2):253-261

20. Megreya AM, Latzman RD, Al-Attiyah AA, Alrashidi M (2016) The robustness of the nine-factor structure of the cognitive emotion regulation questionnaire across four Arabic-speaking middle eastern countries. J CrossCult Psychol 47(6):875-890

21. Jermann F, Van der Linden M, d'Acremont M, Zermatten A (2006) Cognitive emotion regulation questionnaire (CERQ). Eur J Psychol Assess 22(2):126131

22. Zhu X, Auerbach RP, Yao S, Abela JR, Xiao J, Tong X (2008) Psychometric properties of the cognitive emotion regulation questionnaire: Chinese version. Cogn Emot 22(2):288-307

23. Martin RC, Dahlen ER (2005) Cognitive emotion regulation in the prediction of depression, anxiety, stress, and anger. Pers Individ Dif 39(7):1249-1260

\section{Publisher's Note}

Springer Nature remains neutral with regard to jurisdictional claims in published maps and institutional affiliations.

\section{Submit your manuscript to a SpringerOpen ${ }^{\circ}$ journal and benefit from:}

- Convenient online submission

- Rigorous peer review

- Open access: articles freely available online

High visibility within the field

- Retaining the copyright to your article

Submit your next manuscript at $\boldsymbol{s}$ springeropen.com 